\title{
The PICO project: aquatic exercise for knee osteoarthritis in overweight and obese individuals
}

\author{
Flávia Yázigi ${ }^{1 *}$, Margarida Espanha', Filomena Vieira', Stephen P Messier ${ }^{2}$, Cristina Monteiro ${ }^{1}$ \\ and Antonio P Veloso ${ }^{1}$
}

\begin{abstract}
Background: Aquatic exercise is recommended by the Osteoarthritis Research Society (OARSI), by the American College of Rheumatology (ACR) and by the European League Against Rheumatism (EULAR) as a nonpharmacological method of controlling the knee osteoarthritis (KOA) symptoms. Moreover, given that weight loss results in a reduction of the load that is exerted upon the knee during daily activities, obesity is also considered to be a modifiable risk factor for the development and or exacerbation of KOA. The implementation of an exercise based weight loss program may, however, itself be limited by the symptoms of KOA. The aquatic program against osteoarthritis (termed "PICO" in Portuguese) prioritizes the control of symptoms and the recovery of functionality, with an attendant increase in the patient's physical activity level and, consequently, metabolic rate. Our laboratory is assessing the effectiveness of 3 months of PICO on the symptoms of KOA, on physical function, on quality of life and on gait. In addition, PICO shall examine the effects of said exercise intervention on inflammatory biomarkers, psychological health, life style and body composition.
\end{abstract}

Methods/Design: The trial is a prospective, single-blinded, randomized controlled trial, and involves 50 overweight and obese adults (BMI $=28-43.5 \mathrm{~kg} / \mathrm{m}^{2}$; age 40-65 yrs) with radiographic KOA. The participants are randomly allocated into either an educational attention (control) group or an aquatic (exercise program) group. This paper describes the experimental protocol that is used in the PICO project.

Discussion: The PICO program shall provide insight into the effectiveness of an aquatic exercise program in the control of KOA symptoms and in the improvement of the quality of life. As such, they are likely to prove a useful reference to health professionals who intend to implement any kind of therapeutic intervention based around aquatic exercise.

Trial registration: NCT01832545.

Keywords: Aquatic exercise, Knee osteoarthritis, Exercise, Pain, Obesity

\section{Background}

Although rheumatic diseases (RD) have low death rates, they are one of the primary causes of compromised quality of life and absenteeism from work, with attendant economic and social consequences [1]. In Portugal, RD are responsible for 40 to $60 \%$ of situations of prolonged physical incapacity in daily activities, for $43 \%$ of cases of absenteeism from work, and for 35 to $41 \%$ of early retirements due to illness [2].

\footnotetext{
* Correspondence: fyazigi@fmh.ulisboa.pt

'Department of Sports and Health, Univ de Lisboa, Fac Motricidade Humana, CIPER, LBMF, P-1499-002 Lisbon, Portugal

Full list of author information is available at the end of the article
}

Osteoarthritis $(\mathrm{OA})$ is the most prevalent rheumatic disease and represents a great risk to the quality of life of the individual, given the consequent loss of autonomy that can be precipitated by its effect on lower extremity based activities (such as walking up and down stairs, climbing and squatting) $[1,3,4]$. Although the causes of OA are not completely understood, it is thought to be a complex, adaptive response of the joints to biomechanical, genetic and environmental stresses [5]. Recent studies demonstrated that that low-grade inflammation plays a pathophysiological role in OA. The severity, the symptoms, the impairment in physical function and the

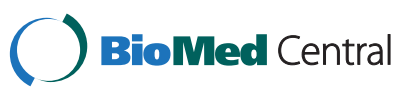


progression of OA may also be partly mediated by the extent of chronic inflammation in OA patients $[6,7]$.

The knee is the most commonly affected weight bearing joint, being considered the $4^{\text {th }}$ and $8^{\text {th }}$ main cause of disability in women and men, respectively [8]. KOA is more common in the medial tibiofemoral compartment than in other sites of the knee, probably due to a higher frequency of varus malalignment [9]. Inflammation and joint loading are commonly believed to cause or to exacerbate the disease process [10]. Obesity, prior knee injury, physical activity levels, physical strength and the extent of alignment/misalignment of body segments are the most often cited potential risk factors for KOA in the academic literature. The latter risk factor seems to have more importance in the radiographic progression than in the incidence of KOA [11-14].

Knee Osteoarthritis (KOA) is highly prevalent in obese individuals [15]. The International Association for the study of Obesity (IASO)/International Obesity Taskforce (IOTF) analysis (2010) estimated that approximately 1.0 billion adults are currently overweight and a further 475 million are obese, worldwide [16]. Obese individuals have higher concentrations of the inflammatory markers (such as TNF- $\alpha$ and leptin) that are predominantly secreted by adipose tissue and can induce the production of IL- 6 and C-reactive protein (CRP) [17]. The pathogenesis of obesity is characterized by hypothalamic inflammation and subsequent central resistance to leptin. High leptin concentrations then compromise the reduction of food intake and increase in energy expenditure. In addition, leptin increases the synthesis of a stimulator of osteophyte formation, TNF- $\beta$ [18]. The resulting lowgrade inflammation plays a pathophysiological role in $\mathrm{OA}$, because it can affect muscle function and lower the individual's pain threshold. It can also affect chondrocyte homeostasis and cause degenerative changes in cartilage $[6,10,19]$.

Besides its effect on the individual's quality of life, KOA uses up considerable health care resources. The consequences of KOA make it a public health problem in many countries [1,20-22]. Pain is the symptom that markedly affects quality of life in KOA patients. Gait tests are an important measure of mobility and KOA patients may adapt their gait and adjust body alignment to reduce pain. However, the latter adaptations may increase the loading on the joint and result in increased disease progression. In addition, the pain that is concomitant with KOA causes irritability, sleeplessness, depression and other physical and psychological changes that may aggravate the disease and incur both a general loss of functionality and a drop or maintenance in physical activity levels to below the recommended levels [23]. The main consequences of inactivity are weight gain and the obesity installation [24]. The combination of obesity and KOA create a vicious cycle of pain, loss of functionality, and disease progression. To interrupt this cycle, KOA symptoms should be reduced. Physical activity and weight loss can make an important contribution.

Current therapy most often focuses on pain relief, using mainly analgesics and nonsteroidal anti-inflammatory medications that have only a modest functional benefit and do not slow disease progression, whilst causing serious cardiovascular and gastrointestinal side effects $[25,26]$. The recommendations of the Osteoarthritis Research Society International (OARSI), the American College of Rheumatology (ACR), and the European League Against Rheumatism (EULAR) also include exercise as an important treatment [27-29]. Aerobic, aquatic, and resistance training exercise are recommended [27].

\section{Exercise program and Knee OA}

Appropriate exercise can provide an improvement in symptoms and reduce pain, preventing OA-associated disabilities and increasing quality of life. In addition, there seems to be a positive effect of exercise on the chondroprotective anti-inflammatory cytokine response [30], mediated by IL-10 and IL-4. The weight loss and body composition improvements that can induced by exercise, reduce the thigh fat depots and may have a positive effect on the secretion of pro-inflammatory cytokines, lowering IL-1 and leptin levels in individuals with KOA [10].

The literature indicates that an exercise intervention for KOA should be broadly based and include aerobic training, lower limb-strengthening, gait training, flexibility, stability and posture training, weight reduction, patient education and psychosocial intervention [27,31-34].

Aquatic exercise is at this moment one of the main non pharmacological interventions that is suggested by the OARSI, ACR and EULAR guidelines as a means of controlling the symptoms and to prevent or slow down the progression of KOA [26,27,35]. Various studies have demonstrated that controlled aquatic exercise classes can be effective for KOA symptom control and to improve function [36-43]. In addition, a person in pain has difficulty with weight bearing exercise. Aquatic exercise allows aerobic exercise to be accomplished with less load on the joints [44].

Several studies have examined the effects of exercise in water (hydrotherapy, aquatic exercise) on the symptoms of knee arthritis [36-40,44-51]. However, said studies are inconsistent as regards the quality and quantity of exercise that was performed. There is a lack of definition of what is involved in hydrotherapy and what is performed in aquatic exercise classes. Aquatic Exercise $(\mathrm{AE})$ is an exercise modality which can be defined as a group of exercises performed in the water, mainly in the vertical position, with or without music, with or without equipment added and in shallow or deep water. Its main 
characteristics are the utilisation of hydrostatic pressure and hydrodynamics to work on the aerobic and neuromuscular system. AE has been used for rehabilitation (hydrotherapy) [52-59], for athletic training [60-64] or for general fitness activity [65-71].

Aerobic training is very important for pain control and to improve functionality in individuals with KOA [27]. According to the guidelines of the Aquatic Exercise Association (AEA) [72], aerobic aquatic exercise classes with fitness goals, should be performed in water between $28-30^{\circ} \mathrm{C}$ so as not to compromising the endocrine responses. Water temperatures above $32^{\circ} \mathrm{C}$ are recommended for passive work, relaxation techniques or for individuals with low movement levels, but are not advisable temperature for aerobic or strength based exercise [64]. In cases of patients with low aquatic abilities, the Arthritis Foundation Guidelines suggest a superior limit range of water temperature of $31^{\circ} \mathrm{C}$ [73].

The PICO program is an overall body fitness and mind based intervention through aquatic exercise involving an educational component that has been specifically created for individuals with KOA. Two recent studies regarding the aquatic exercise in KOA should be referred to $[38,39]$, as they have a controlled methodology and were performed according to the AEA guidelines [72].

\section{Study aim}

To design an aquatic exercise program specific to knee osteoarthritis, with the goal of management of OA symptoms and the improvement of physical fitness. The PICO program is based around the first step for weight loss interventions in individuals with KOA being the control of pain and other symptoms. When KOA symptoms are controlled, patients learn that it is possible to live with the disease which in turn motivates lifestyle changes. The increase of physical activity due to lifestyle changes may then cause improvement in body composition. In this way 6 hypotheses are formulated: H1. 3 months of aquatic exercise will improve KOA symptoms (pain and stiffness) and physical function in obese individuals with KOA; H2. The gait parameters (gait speed, gait cycle, ground reaction forces and knee forces moments) of obese individuals with KOA can be improved by aquatic exercise; H3. Beyond fitness component and the exercises skills, aquatic exercise group classes can work as an educational component and to promote lifestyle changes. H4: The aquatic exercise program can improve mental status and quality of life. H5: The aquatic exercise program can cause a weight reduction or body composition change. H6: 3 months of aquatic exercise can have a positive effect on selected inflammatory biomarkers of KOA.

\section{Design/Methods}

\section{Study design}

PICO is a single-blinded, randomized controlled trial with 3 months duration. Participants will be randomly assigned to one of two groups: aquatic exercise (AE) and control group (CG). Figure 1 provides a flowchart of PICO design. Researchers and personnel responsible for data collection will be blinded four the group classes. The study protocol was approved by the Ethical Committee of the Faculty of Human Kinetics, Technical University of Lisbon. All participants will be informed about the procedures and potential risks and an informed consent will be obtained from them.

\section{Sample}

Considering the calculation of the sample size, the studies of Messier (2009) [74] and Wang (2007) [44] were used as a reference, because they had a sample with similar characteristics and studied similar outcomes. Both showed that a reduction of symptoms in patients with OA of the knee led to a significant improvement $(\alpha<0.05)$ of the primary outcome measure of self-reported physical function. To find an analogous improvement of self-reported physical function of approximately $25 \%$ between the baseline and final measurements in patients with KOA, the minimum number of patients that are required is 20 for the main outcomes. The latter number is based on a power (1-B) of 0.80 and a significance level of $5 \%$ (two-sided). When a dropout rate of $20 \%$ is taken into account, at least 25 participants must be involved at study onset.

\section{Inclusion criteria}

The study sample will consist of 56 community-dwelling adults from the Lisbon area with: (1) age between 40 and 65 years; (2) $28.0 \leq \mathrm{BMI} \leq 45 \mathrm{~kg} / \mathrm{m}^{2}$; (3) unilateral or bilateral KOA diagnosed by knee pain and grade I-III radiographic tibiofemoral OA or tibiofemoral plus patellofemoral OA (4) a sedentary lifestyle, defined as not participating in a program that incorporates more than 30 minutes per week of formal exercise, within the 6 months leading up to the study; (5) being independently mobile; and (6) literate.

\section{Exclusion criteria}

The exclusion criteria are: subjects with skin diseases, with unstable medical conditions and or who have undergone hip or knee replacement, or knee surgery within the 6 months prior to the study; and participants who had any type of knee injections within the past 3 months.

\section{Trial conduct}

\section{Recruitment}

The recruitment and selection process will be done according to the aforesaid eligibility criteria. To avoid 


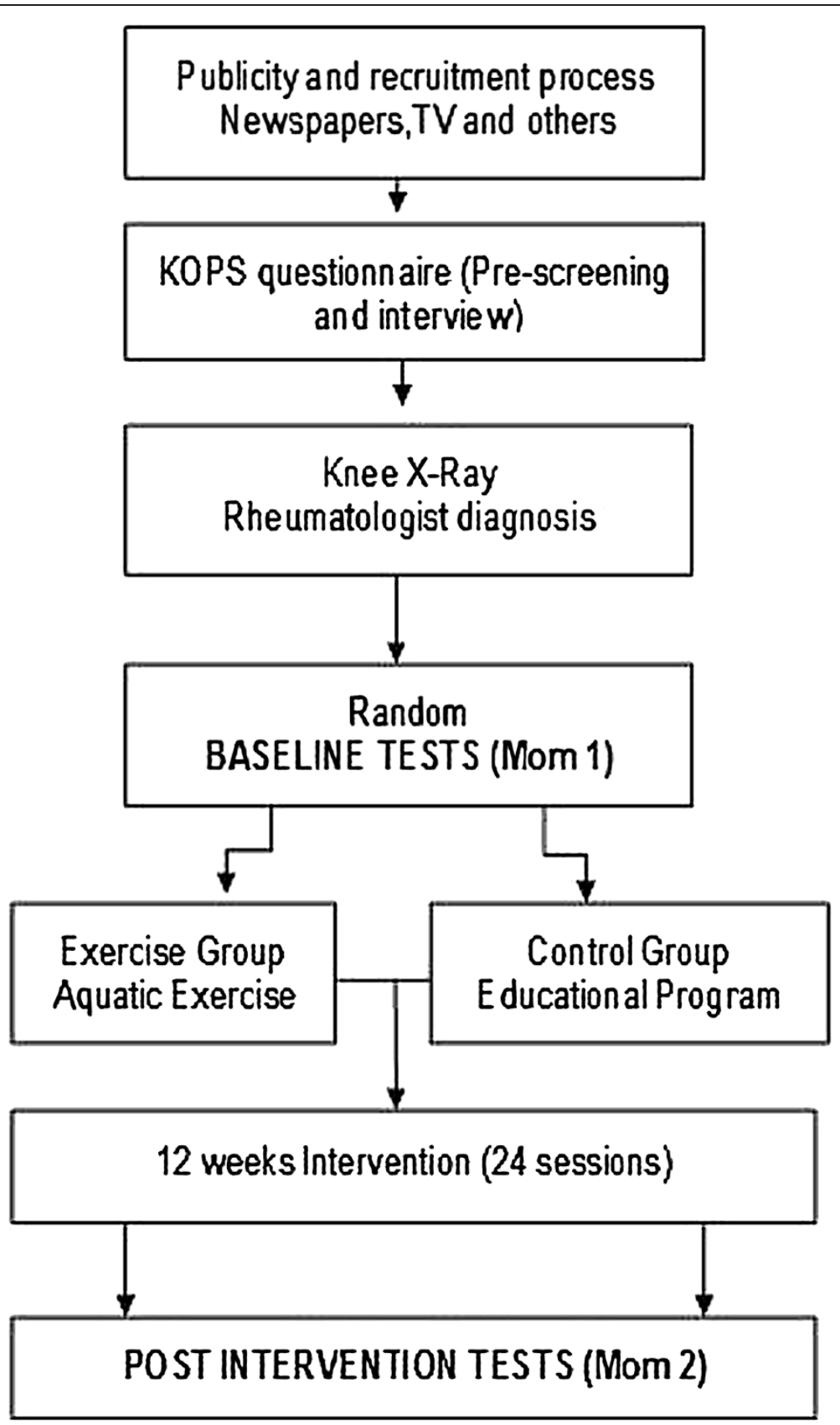

Figure 1 PICO flowchart.

convenience sampling different documents will be created for advertising and publicizing the PICO project. Social networks, television interviews, newspapers and the collaboration of entities/companies will be the main channels for PICO announcements.

All eligible individuals who contact the study secretariat will go through the same selection process, namely: a telephone based pre-selection stage followed by a face to face interview and completion of the screening questionnaire which will supply information about demographics and symptoms, signs and risk factors for KOA occurrence. Volunteers who, after completing the questionnaire, fulfill the ACR criteria for clinical diagnosis [75] will receive a request for an x-ray examination. The exams will be referred to a rheumatologist who will make the final diagnosis according to ACR radiological criteria. In the case of confirmation of the KOA diagnosis, the subject will be invited to a further interview the purpose of which is 
detailed explanation of the project, obtaining his/her informed consent and familiarization with both the locale and the equipment which shall be used in the tests.

\section{Intervention programs}

\section{Aquatic exercise (AE)}

The aquatic program is based on the guidelines of OARSI and EULAR for KOA management [28,29], on the Aquatic Exercise Association Guidelines (AEA) [72], on the Arthritis Foundation Aquatics Program instructor's manual [73], on the ACSM's Guidelines for Exercise Prescription [76] and on analysis of the protocols of previous studies [36,38,39,44,77,78].

The strategies in the PICO proposal to produce a high quality aquatic exercise intervention are structured according to AEA guidelines [72] and include overload assessment and managements, impact level control (level 1, 2 or 3), exercise cadence control and adequate music according to exercise goals. In addition the use of different and pre-defined cool-down sessions each week, a strong motivational component and pain assessment should make the difference in this protocol. Educational themes shall also be addressed during the classes. One educational theme per week shall be reinforced, such as:
What did you have for breakfast? Let's try, during this week, to improve the quality of our breakfast. Next class I will check what you ate; remember that you should assess yourself about knee pain, let's try to learn how to live with it.

Another aspect that will be considered is the level of aquatic ability of each participant. Exercises like underwater breathing and flotation will be used in small doses to reduce fear of water and to ensure that participants are comfortable moving around the pool.

The aquatic program will be organized into 24 sessions distributed over 12 consecutive weeks, with a frequency of twice a week. The duration of each session will be 60 minutes, being that 10 minutes are for patient reception, blood pressure control, pain registry etc., and the effective time inside the water is 45 minutes. The indoor pool works with an air temperature around $27 \pm 1^{\circ} \mathrm{C}$ and water temperature is controlled at $30.5 \pm 0.5^{\circ} \mathrm{C}$.

Table 1 describes the aquatic exercise class format for the first four weeks. Workouts are organized in order to have a progressive overload every week. Water is the main instrument to create resistance and only in the last week, according to the level of progression of the participants and whether their self-reported pain is controlled,

Table 1 The aquatic exercise protocol design for the first 4 weeks of the PICO program

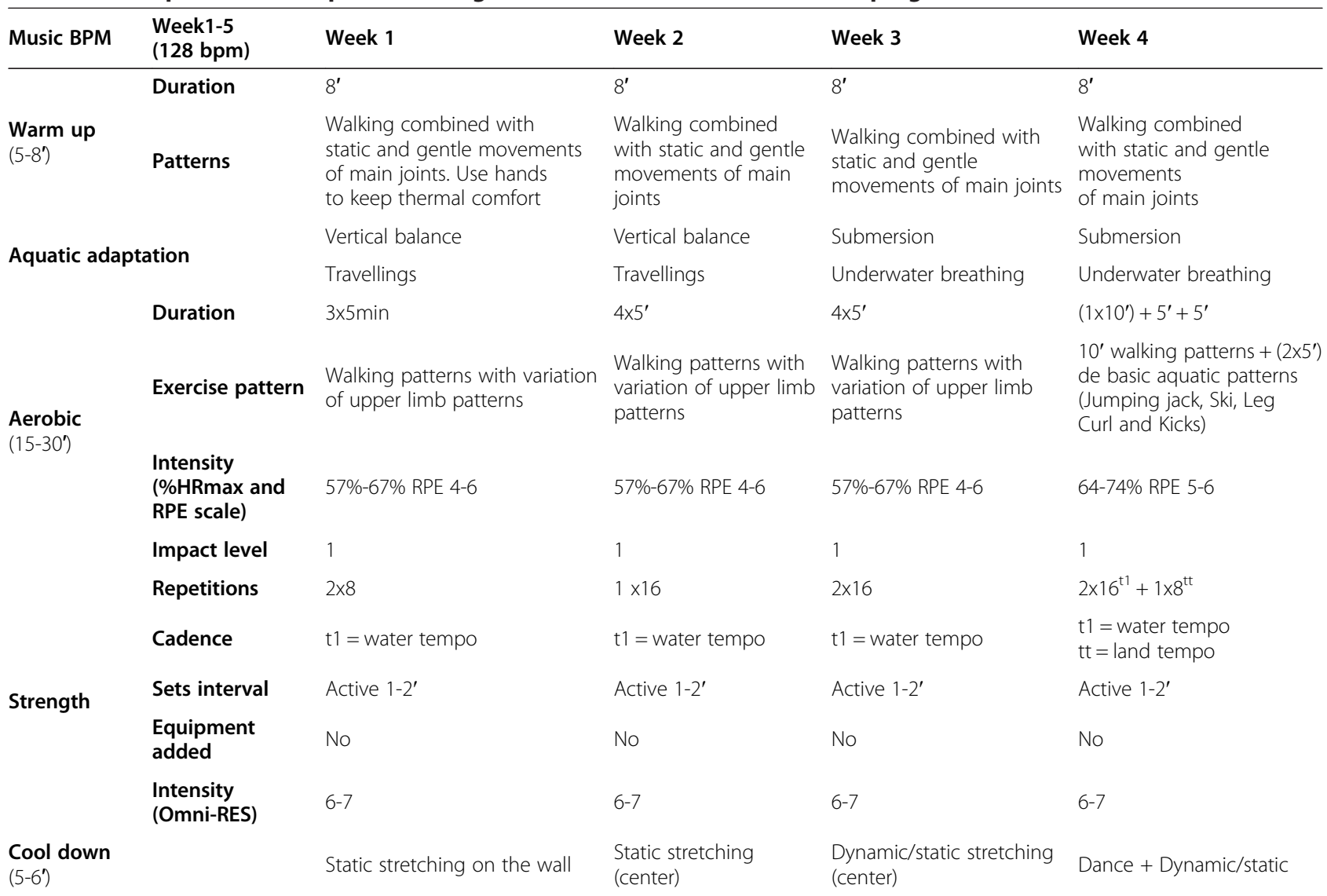


will additional equipment be added to increase the water resistance and consequently, the exercise overload. The Omni - Perceived Exertion Scale for Resistance Exercise (OMNI-RES) and for aerobic target zone (0-10 Borg Scale) will be used according guidelines for exercise intensity management [76].

The exercise instructors will use behavioral techniques: 1) to encourage social contact between participants; 2) to promote frequent contact during all intervention phases; 3) to define clear behavioral goals and allow feedback on achievements; 4) to help participants to self-monitor their pain and exercise intensity to complete activity; 5) to establish personal commitment to the project through the exercise leader.

\section{Educational program: control group (CG)}

The control group will not be enrolled in any exercise program but will participate in the educational program "PESO comunitário". This program is based on appropriate clinical guidelines and on validated behavior change principles [79]. Implemented by an intervention team with expertise gained from current scientific research in weight control determinants, this program, as is PICO, is free of charge for all interested adults who wish to manage their weight and health. It has operated since 2005 with the objective of preventing obesity or reducing excess weight as well as some of the risk factors for adult obesity, via through a change to steady healthy habits, attitudes and behaviors. PESO lasts 3 months and comprises 12 sessions of one and a half hour, on a weekly basis.

\section{Measurements}

\section{Screening measurements}

The Knee Osteoarthritis Pre-Screening questionnaire (KOPS) was validated by the authors and considered useful for this purpose (article in submission process). KOPS addresses physical function, activity level, co-morbid diseases, KOA risk factors and symptoms, height and weight (to determine BMI) as well as caregiver status. The demographic data that are collected include data on occupation, income, and educational level. The medical form is used to determine co-morbidities and to analyze any selfreported information on medications. The overall KOPS score has acceptable to good reliability with a Cronbach's Alpha of 0.747 and satisfactory internal consistency with an Intraclass Coefficient (ICC) for average measures of 0.646. The results for test-retest of one-week interval for each component ranged from 0.895-0.992 for ICC and from 0.894 to 0.979 for Cronbach's Alpha.

\section{Osteoarthritis diagnosis and severity classification}

To confirm OA and classify its severity the same X-ray protocol will be used for all subjects. Bilateral, anteriorposterior, weight-bearing knee radiographs will be used to identify OA in the tibiofemoral joint, and sunrise views to identify $\mathrm{OA}$ in the patellofemoral compartment. Severity of tibiofemoral OA will be measured using the $\mathrm{K}-\mathrm{L}$ grading scale [80].

\section{Outcomes, measures and instruments}

All tests will be performed by all subjects at both baseline and 3 month later, at the end of the exercise intervention, using the same protocols and evaluated by the PICO team member(s). Tests list can be checked in the Table 2. The tests and questionnaires will be distributed over two nonconsecutive days, taking the fatigue levels of the subject and the need to avoid overload into account. Therefore the knee strength test and the Six Minute Walking Test will be conducted on different days.

The main outcomes will be KOA symptoms (pain and stiffness) and quality of life, physical function (aerobic

\section{Table 2 Tests list}

\begin{tabular}{|c|c|c|c|}
\hline ASSESSMENT (TEST) & Screening & Baseline & $\begin{array}{c}3 \\
\text { months }\end{array}$ \\
\hline \multicolumn{4}{|l|}{ Recruitment } \\
\hline Interview & $x$ & & \\
\hline KOPS & $x$ & & $x$ \\
\hline $\begin{array}{l}\text { Knee X-ray (lateral and } \\
\text { antero-posterior) }\end{array}$ & $x$ & & \\
\hline \multicolumn{4}{|l|}{$\begin{array}{l}\text { KOA symptoms and quality of life } \\
\text { (Self-reported questionnaires) }\end{array}$} \\
\hline Pain assessment (Brief pain inventory) & & $x$ & $x$ \\
\hline $\begin{array}{l}\text { Knee osteoarthritis associated quality } \\
\text { of life (KOOS) }\end{array}$ & & $x$ & $x$ \\
\hline MOS (SF-12v2) & & $x$ & $x$ \\
\hline $\begin{array}{l}\text { Depression assessment } \\
\text { (Beck depression inventory) }\end{array}$ & & $x$ & $x$ \\
\hline Weight and lifestyle inventory & & $x$ & $x$ \\
\hline \multicolumn{4}{|l|}{ Physical function and gait } \\
\hline Aerobic capacity (6MWT) & & $x$ & $x$ \\
\hline Strength & & $x$ & $x$ \\
\hline Functional (FRSTS) & & $x$ & $x$ \\
\hline Knee (BIODEX dynamometer) & & $x$ & $x$ \\
\hline Hand (grip dynamometer) & & $x$ & $x$ \\
\hline Flexibility (CRS and BS tests) & & $x$ & $x$ \\
\hline Gait Analysis (Kinematics and kinetics) & & $x$ & $x$ \\
\hline \multicolumn{4}{|l|}{ Morphology and body composition } \\
\hline $\begin{array}{l}\text { Morphological measures } \\
\text { (Anthropometry) }\end{array}$ & & $x$ & $x$ \\
\hline Body composition (DXA scan) & & $x$ & $x$ \\
\hline \multicolumn{4}{|l|}{ Life style } \\
\hline Physical activity level (IPAQ) & & $x$ & $x$ \\
\hline \multicolumn{4}{|l|}{ Inflammation biomarkers } \\
\hline Cytokines (blood drawn) & & $x$ & $x$ \\
\hline
\end{tabular}


capacity, strength, and flexibility) and gait (kinetics and kinematics). The secondary outcomes are body composition, morphology, physical activity level, and inflammatory biomarkers. During the study, all participants will be allowed to maintain their usual medication, including analgesics and NSAIDs. A detailed record of medication will be done at baseline and 3 month post-intervention testing.

\section{Knee OA symptoms and health quality of life}

Brief Pain Inventory (BPI) - short version. A consensus panel, the Initiative on Methods, Measurement, and Pain Assessment in Clinical Trials (IMMPACT) recommended the inclusion of the short version of Brief Pain Inventory (BPI) in all trials that intend to assess chronic pain [81]. It is a widely used, reliable, valid instrument that assesses pain history, location, intensity and its interference with daily activities in individuals with osteoarthritis [82]. The Portuguese version was validated and recent studies have provided strong support for its reliability and validity $[83,84]$.

Numerical Rating Scale (NRS). The subjects shall learn to self-assess their knee intensity pain via the 0-10 point NRS. The NRS should be used to control pain intensity before and after the aquatic exercise class and whenever is necessary.

\section{Knee Injury and Osteoarthritis Outcome Score} (KOOS). This questionnaire includes 5 dimensions to measure KOA specific health-related quality of life (QOL), knee pain (Pain), other disease-specific symptoms (Other Symptoms), activities of daily living (ADL), sport/recreation function (Sport/Rec). A score in each of the five dimensions is calculated as the sum of the items included and then converted according to a 0-100 scale, with 0 representing extreme knee problems and 100 representing no knee problems. The KOOS is validated for patients with knee injury or with knee OA and is a reliable and responsive self-administered instrument for short-termfollow-up [85]. The Portuguese validation has acceptable reliability with Cronbach's alpha coefficients between 0.77 and 0.95, and ICC ranging from 0.82 to 0.94 for the KOOS subscales [86]. Medical Outcomes Study (MOS) Short-Form Health Survey (SF-12v2). SF-12 v2 consists of a subset of 12 items to assess health status, organized into two domains: Physical (Physical Component Summary, PCS) and Psychological (Mental Component Summary, MCS) that make up the original SF-36 [87]. It has been shown that the SF-12 correlates highly with SF-36 in both obese and non-obese patients [88]. The Portuguese version of SF-12 has satisfactory reliability and validity $[89,90]$.
Beck Depression Inventory (BDI-II). This

instrument, developed by Beck and colleagues [91] has 21 items to rate the severity of depression according to the clinical definition. It is one of the most popular and widely used instruments for assessing the severity of depressive symptomatology. The Portuguese version [92] shows a good internal consistency, a factor structure very similar to the original version [91,93], and an adequate convergent validity.

\section{Physical function}

Six Minutes Walking Test (6MWT). The distance (d) and gait speed (v) of the 6MWT is used to assess the aerobic capacity and the walking ability. It will be performed individually and according to the American Thoracic Society protocol (ATS) [94], in a controlled indoor environment 46 meters in length and rectangular in shape. The $6 \mathrm{MWT}$ is highly reproducible in obese individuals $(\mathrm{r}=0.926$; 95\% CI $0.816-0.972, \mathrm{P}<0.001$ ) [95], and it has been used in studies with KOA [75,96-100].

Chair Sit and Reach test (CSR). The CSR test is a safe and socially acceptable alternative to traditional floor sit-and-reach tests as a reasonably accurate and stable measure of hamstring flexibility [101]. The subjects shall be allowed three attempts for each limb and the best of these scores shall be recorded to the nearest centimeter.

The Back Scratch Test (BS). The BSS is a measure of overall shoulder range of motion which involves measuring the distance between (or overlap of) the middle fingers behind the back with a ruler [102]. After a familiarization trial, this test is assessed twice, alternately with both hands, and the best value of each registered.

Five-Repetition Sit-To-Stand Test (FRSTST). This is a widely used measure of functional strength. ICC values for it demonstrate from good to high test-retest reliability for adults and subjects with osteoarthritis $[100,103,104]$.

\section{Strength}

Knee Strength. A dynamometer Biodex System III (Biodex Medical Inc., Shirley, NY, U.S.A.) will be used for isokinetic assessment of knee strength (flexor and extensor muscles) and isometric knee strength, bilaterally. The first leg to be tested shall be the less affected leg or, in doubtful cases, the dominant leg. Gravity correction to torque is calculated at 45 degrees $(0=$ straight leg). The range of motion for testing is pre-determined from $20^{\circ}$ to $80^{\circ}$ for all subjects. The exclusion of extreme ranges of knee motion was 
established due to the fact that they are known to be painful and frequently non-executable by these patients, namely full extension due to quadriceps weakness Similar procedures, according to the dynamometer used, have been adopted in other surveys involving the same population [105-110].

Maximal Isokinetic Strength is measured on a concentric/concentric mode, at angular velocity of $60^{\circ} / \mathrm{s}$. Among the low velocities' group, the $60^{\circ} / \mathrm{s}$ have been used in other studies and should provide better stability for this population [111]. The subjects should perform one set with minimum overload for habituation and 2 sets of 3 repetitions with a 120-second rest between sets. The subjects should be oriented to perform the test by exerting maximum pressure on the isokinetic arm through the entire range of movement. During the test vigorous verbal encouragement shall be given to each subject. The set with higher extension peak torque together with the lowest coefficient of variation will be chosen for analysis.

The angle of best torque of the knee extension obtained from each subject in the isokinetic test should be chosen for the isometric test. Maximal knee extension isometric test will be applied in one set of 3 repetitions during 5 seconds with 30 seconds relaxation interval between repetitions. The best of the three force-time curve will be chosen according to the higher peak.

Prior to measurement, the subject shall be are seated on the dynamometer with knee and hip joints at $90^{\circ}$. Crossover shoulder, belly and knee straps, as well as a lap belt will be used to restrain the subjects movement. The lever arm pad is strapped around the lower leg, 2 centimeters above the lateral malleolus of the fibula. The axis of rotation of the dynamometer should be aligned with knee joint's axis of rotation. Joint warm-up will be done by gentle free movements of flexion and extension of the knee.

The Handgrip Strength Test (HST). This test evaluates maximal isometric force of the muscles of the hand and forearm. Although the sample of this study will not have hand OA, this test has been used in obese individuals as an indicator of total body strength and functionality $[112,113]$. The adopted protocol for this project is the same that was used for Portuguese adults in the national observatory [114]. Prior to the test, the grip dynamometer should be adjusted to the size of the hand of each subject. Subject will be standing with arms along the body without contact with the trunk and elbow slightly bent at $200^{\circ}$. Testing is first done by dominant hand followed by the non-dominant one. The force must be performed during the expiratory phase and valsalva maneuver should be avoided. After three trials, if the difference between each value is within $3 \mathrm{~kg}$, the test is considered completed. If a bigger difference is observed, then the test will be repeated after sufficient rest time. The best repetition will be chosen for further analysis.

\section{Morphology and body composition}

Body composition. Body mass index will be calculated as mass (measured in kilograms by a standard calibrated scale) divided by height squared (measured in meters). A DXA scanner (QDR 4500A, fan-beam densitometer, software version 8.21; Hologic, Waltham, USA) will be used to measure whole body lean mass (LM), fat mass (FM) and bone mineral content (BMC). DXA measures the attenuation of X-rays pulsed between 70 and $140 \mathrm{kV}$ synchronously with the line frequency for each pixel of the scanned image. According to the protocol described by the manufacturer, a step phantom with six fields of acrylic and aluminum of varying thickness and known absorptive properties shall be scanned alongside each subject to serve as an external standard for the analysis of different tissue components. The same technician shall position the subjects, perform the scans and execute the analysis using the standard analysis protocol. Based on test-retest using 10 subjects, the coefficient of variation $(\mathrm{CV})$ in PICO staff for FM and FFM was 2.6 and 1.5\% respectively, and the total error of measurement (TEM) and the CV were $0.02 \mathrm{~kg}$ and $1.7 \%$ respectively.

Anthropometry. The anthropometric measurements that shall be collected by this study shall include height, body mass, perimeters (waist, hip, middle thigh, patella shank and foot breadth. The aforesaid measures shall be collected by an ISAK accredited anthropometrist using procedures established by ISAK [115] except in the case of patellar circumference, foot diameter and abdominal sagittal diameter, which shall be obtained according to previously validated procedures [116-118]. The intra-observer technical error for circumferences and diameters measures in the pilot study ranged from $0.2-0.4$.

\section{Gait analysis}

The gait protocol used on the present study was adapted from IDEA study [77], taking into account our laboratory specific equipment.

Data collection and analysis: Motion capture of the gait will be collected with 10 cameras Qualisys (Oqus-300) operating at a frame rate of $200 \mathrm{~Hz}$. Forty six reflective markers should be placed in predefined anatomical protuberances and used for the reconstruction of lower limb segments using Visual 3D software (C-Motion, Inc., Germantown, MD). To reduce noise, the motion data is filtered, using a low pass Butterworth filter, 
with a cutoff frequency of $15 \mathrm{~Hz}$ [119]. Ground reaction force will be collected with two force platforms (Kistler AG, Winterthur, Switzerland) and AMTI (Advanced Mechanical Technology, Inc, Watertown, MA), synchronized with the motion capture system.

The test will be performed in a fifteen meters walkway, six successful trials are collected from each participant and three should be chosen for subsequent analysis. A trial consists of starting on the platform approximately 2 meters behind the initial timer and walking past the first beam of light to activate the timer. As the participant walks and passes the second beam of light the timer will stop and speed will be recorded. The participant will turn around and wait for orientations to perform similar trial in the opposite direction.

In general, KOA subjects walk at a slower speed and cadence, with a prolonged stance phase, presenting a static and dynamic varus alignment, showing smaller flexion and greater knee adduction moment (KAM) $[12,34,120,121]$. The following kinematic and kinetic outcomes should be analyzed from the gait test:

\section{Gait speed}

Freely chosen speed is slower in individuals with Knee OA being correlated with high ground reaction forces during heel strike [77];

\section{Gait cycle characteristics}

Swing and stance phase duration, stride frequency, stride length, knee and hip ROM and angular velocity;

\section{Ground reaction forces}

The vertical, anteroposterior and mediolateral force components will be recorded with a force platform. Computer software will be used to calculate duration, amplitude and impulse of the reaction forces;

\section{Knee adduction moment (KAM)}

Knee adduction moment (KAM) is considered a valid parameter to infer the level of mechanical loading [122]. Healthy subjects show substantially higher abduction moments than OA subjects and the external adductor moment has been linked to the development and progression of medial compartment OA in association with the varus alignment installation by increasing the compressive forces across the knee [123]. In addition, there is a significant inverse association between the peak of knee adduction moment during late stance and the amount of knee pain which may represent a compensatory mechanism to reduce medial tibiofemoral joint load in the setting of knee pain [124];

\section{Adduction angular impulse (AddImp)}

The integral of the frontal plane external joint moments (adduction and abduction) over time during the stance phase, providing a functional measure of gait rather than normalized KAM. This measure has been useful to distinguish loads in different OA severity $[125,126]$;

\section{Knee extension moment}

Individuals with knee pain and weak muscles, as a protective mechanism, seem to avoid the quadriceps muscle recruitment during load acceptance in stance phase, showing a reduced knee peak extension moment;

\section{Hip extensor moment}

OA subjects walking at similar speeds of healthy one's maintain their walking speed by increasing hip range of motion and its speed. Greater hip extensor moments may indeed help to maintain walking speed, but this does not appear to be the case with the hip flexor and ankle plantar flexor moments, which were substantially lower;

\section{Hip external abduction moment}

Individuals with knee OA seems to have a higher involvement of hip adductor muscles to compensate a weak quadriceps and hip abductors [12,127].

Since this is a longitudinal study, walking speed may change and should be measured at each testing moment (baseline and after intervention). One successful trial is defined as the one in which the participant's entire foot is placed on the surface area of the force platform while walking within $\pm 3.5 \%$ of the freely chosen speed.

The freely chosen speed should be assessed in the biomechanical test day before the placement of markers, in so far as each subject shall walk barefoot in the walkway until a stabilization of walking speed is observed. Usually the latter stabilization occurs after crossing of the walkway 5-6 times. The speed is monitored using an infrared photocell control system (Model E3F2-R4B4-M, OMRON) set with $7.3 \mathrm{~m}$ apart at the hip level, interfaced with a processor specifically built to record the time and calculate the speed as a function of the distance.

\section{Lifestyle \\ International physical activity questionnaire (IPAQ)}

The short form of IPAQ was chosen because it is easy to apply. Despite its liability having been verified in many countries and with different populations [128-130], studies have indicated that the IPAQ-SF typically overestimates physical activity [131]. However, this instrument will be used for controlling the amount of physical activity along the study, and not for any classification of physical activity level. All participants shall receive a previous explanation about how to complete the questionnaire, and their 
answers will be confirmed during the interview. Data will be processed according to IPAQ guidelines [132].

\section{The weight and lifestyle inventory (WALI)}

The WALI is designed to obtain demographics information, weight and dieting histories, eating and exercise habits, and relationships with family and friends [133]. The Portuguese version (IPEV) and the process by which it was translated is published in a national book [134]. The PICO project will use only the sections G, K and Q of the Portuguese version (IPEV) for controlling alcohol and tobacco consumption, dietary patterns and clinical historic.

\section{Inflammatory biomarkers}

Our primary measures are IL- 6 and IL-10. These cytokines are consistently implicated in $\mathrm{OA}$ pathogenesis and showed significant improvement with weight loss in ADAPT. We will also measure hsCRP as an overall marker of chronic inflammation and TNF $\alpha$ and TNF $\alpha$ soluble receptor 1 (sTNFR1) because they are also implicated in OA pathogenesis. Leptin, an adipokine that increases synthesis of TGF $\beta$, a known stimulator of osteophyte formation, will also be measured.

For assessing IL-6, IL-10, hsCRP, TNF $\alpha$, sTNF $\alpha$ R1 and leptin, venous blood samples (approximately $10 \mathrm{ml}$ per visit) will be collected into dry tubes and EDTA tubes by standard procedures in the morning after a minimum of $4 \mathrm{~h}$ fast without any type of exercise.

Blood will be centrifuged at $1500 \mathrm{x}$ g for $10 \mathrm{~min}$ to separate serum from the cloth in the dry tubes and plasma from red blood cells in the EDTA tubes. Serum and plasma will be frozen at $80^{\circ} \mathrm{C}$ for posterior analysis by ELISA using commercially available kits.

\section{Statistical analysis}

Descriptive statistics, including frequencies for categorical variables and means with standard deviations (SD) for continuous variables with normal distribution and median for skewed distributions will be used to describe subject's characteristics. Normality will be tested using the Kolmogorov-Smirnov test. For continuous outcome measures, differences in mean change (baseline minus post-intervention) will be compared between groups using analysis of covariance adjusted for baseline values of the outcome. Comparisons between groups (CG and AEG) at baseline and post intervention will be conducted by Independent-sample t-tests or Mann-Whitney $U$ test if equal variance is not assumed. Changes within group will be analyzed by paired Student's t tests or by the Wilcoxon Signed Rank test when normality is not assumed. A mixed model analyses of covariance (ANCOVAs) will be conducted for interaction analyses adjusted for BMI with two within-participant factors of 6MWT (baseline) and
6MWT (post-intervention) and between two groups (CG and AE). Statistical analysis will be performed using IBM SPSS Statistics 20.0 and MedCalc Statistical Software (MedCalc Software, Mariakerke, Belgium). Multiple Linear regression analyses will be performed to understand the potential covariates that could improve the explanation of the variability of outcomes (6MWT, strength and KOOS dimensions). Statistical significance will be set at $\mathrm{P}<0.05$ (2- tailed) for all analyses. Effect sizes will be calculated for all measures with an effect size of 0.2 considered small, 0.5 medium and 0.8 large.

\section{Discussion}

The need to improve non-pharmacological intervention for patients with KOA is obvious, and aquatic exercise is an option for obese patients since it minimizes joint load. Although water exercise is frequently encouraged, relatively little research has been conducted in this area as compared to land-based exercise.

There are several strengths to the design of this study. The first one, is the detailed exercise prescription protocol concerning dosage (frequency, duration and intensity of the exercise), the fulfillment of overload and individuality principles of training (e.g., gradual increase of the number of sets and repetitions on strength training), and the control of exercise intensity during the sessions using rating perception effort scales (e.g., Borg RPE and Omni scales).

Secondly, the pool where the program will be delivered is easily accessed by train or bus. This aspect is crucial as the access to appropriate facilities and patient motivation to undertake water exercise, might be a barrier to adherence. Additionally, the fact of our sample being adult and not elderly should facilitate the displacement to our facilities.

Thirdly, the exercise program will be delivered by high qualified aquatic exercise instructors, all of whom shall be graduates in Sports Science at the Faculty of Human Kinetics who have specialized in exercise and health and fitness group skills. The exercise program will be delivered similarly to both classes regarding exercises, overloads and leading strategies according to the predefined plan. Four instructors will be organized in pairs, and each pair will take care of one aquatic exercise group during the entire program.

With the exception of the knee radiographs for OA diagnosis, all measures will be obtained in the same facility at the baseline and immediately after the end of the program. One barrier at each visit/measuring point will be the capacity to asses all participants in a short interval. Due to the specificity of the outcomes will be necessary to manage the schedule among four different labs. Therefore, to support the project, staff team includes one secretary responsible for administrative work, 
four technicians conducting the dynamometer tests, gait analysis, body composition and anthropometry assessments and one professional for collecting blood samples. Each technician received the responsibility to be specialized in two test's group plus questionnaires and, to avoid inter-rater error, the same technician should lead its application in both assessments, baseline and post-exercise intervention. Participant adherence to exercise is one of the main challenges, therefore to avoid drop outs, motivational cues, intra-group social interaction, frequent telephone calls and the quality of instructors are the main strategies chosen to contribute to adherence rates. Besides, since our sample will include adults that may still be working which will create some difficulties in the definition of class schedules, one extra class, every 15 days, will be provided to enhance high compliance, and to allow that all participants might attend to 24 sessions during the 3 month period over which the study shall run.

One possible constraint to the success of the aquatic exercise programs would be the level of water skills of each participant. Although it is not necessary to know how to swim, the autonomy and the ability to apply power against the water are essential to get benefits from this type of activity, especially when performing strengthening exercises. Therefore some aquatic adaptation exercises will be introduced in the class format (Table 1).

Our study is based on the premise that individuals with KOA need a wide exercise intervention, adapted not only to the affected joint but to the health status of the patient, working the whole body and the mind simultaneously. In addition, we expect that aquatic exercise, beyond the improvement of KOA symptoms, can increase the symmetry between forces in the lower-limb joints (adduction/abduction and flexion/extension moments at knee and hip joints), so improving gait.

The format of the sessions, the study duration and the weekly frequency of exercise classes are organized in such a way as to make sure that this proposal is executable, not only for this project but also for future implementations by communities or in private pools. The sample size of this protocol are reduced because we consider that, before implementing the program in the general community, for public health, the exercise protocol should be validated by a very controlled process.

\section{Conclusions}

This study is a Randomized Controlled Trial (RCT) using aquatic exercise specially designed with a very controlled methodology. It is expected that the results will enable evidence-based recommendations for the treatment of patients with KOA through aquatic-exercise. Future studies would aim to reproduce the protocol contained herein and implement it in a larger sample and in different communities. The findings of PICO's aquatic program for
KOA should inform the development of an effective and reproducible exercise protocol, available for use by any professional with aquatic exercise and exercise and health related knowledge.

\section{Competing interests}

The authors declare that they have no competing interests.

\section{Authors' contributions}

FY conceived the study, participated in its design and coordination, shall carry out the biomechanical gait tests, the intervention team coordination and drafted the manuscript. ME participated in its design, coordinates staff, and improved both the manuscript improvement and data management. SM participated in the protocol development, and in training staff for biomechanics tests. FV participated in the design of the body composition and anthropometry based protocols and their coordination. CM coordinates and carries out the biomarker analyses. AV participated in the study design and manuscript improvement. All authors read and made comments on previous drafts of the manuscript, and approved the final manuscript.

\section{Acknowledgements}

We gratefully acknowledge the contributions to this paper of our colleagues and also, a special thanks to Professor Veronica Vleck for the final revision.

\section{Author details}

'Department of Sports and Health, Univ de Lisboa, Fac Motricidade Humana, CIPER, LBMF, P-1499-002 Lisbon, Portugal. ²Department of Health and Exercise Science, Wake Forest University, Winston-Salem, NC, USA.

Received: 29 May 2013 Accepted: 7 November 2013

Published: 13 November 2013

\section{References}

1. Arden N, Nevitt MC: Osteoarthritis: epidemiology. Best Pract Res Clin Rheumatol 2006, 20:3-25.

2. DGS: Programa nacional contra as doenças reumáticas: circular normativa, Saúde DGd ed., vol. 12 DGCG edition. Portugal: DGS; 2004.

3. Gabriel SE, Michaud K: Epidemiological studies in incidence, prevalence, mortality, and comorbidity of the rheumatic diseases. Arthritis Res Ther 2009, 11:229.

4. Issa SN, Sharma L: Epidemiology of osteoarthritis: an update. Curr Rheumatol Rep 2006, 8:7-15.

5. Dieppe P: Osteoarthritis. Acta Orthop Scand Supp/ 1998, 281:2-5.

6. van der Kraan PM: Osteoarthritis year 2012 in review: biology. Osteoarthritis Cartilage 2012, 20:1447-1450.

7. Rai MF, Sandell LJ: Inflammatory mediators: tracing links between obesity and osteoarthritis. Crit Rev Eukaryot Gene Expr 2011, 21:131-142.

8. Williams F, Spector T: Osteoarthritis. Medicine 2006, 34:364-368.

9. Winby CR, Lloyd DG, Besier TF, Kirk TB: Muscle and external load contribution to knee joint contact loads during normal gait. J Biomech 2009, 42:2294-2300.

10. Messier SP: Obesity and osteoarthritis: disease genesis and nonpharmacologic weight management. Rheum Dis Clin North Am 2008, 34:713-729.

11. Cerejo R, Dunlop DD, Cahue S, Channin D, Song J, Sharma L: The influence of alignment on risk of knee osteoarthritis progression according to baseline stage of disease. Arthritis Rheum 2002, 46:2632-2636.

12. Chang A, Hayes K, Dunlop D, Song J, Hurwitz D, Cahue S, Sharma L: Hip abduction moment and protection against medial tibiofemoral osteoarthritis progression. Arthritis Rheum 2005, 52:3515-3519.

13. Cooper C, Snow S, McAlindon TE, Kellingray S, Stuart B, Coggon D, Dieppe PA: Risk factors for the incidence and progression of radiographic knee osteoarthritis. Arthritis Rheum 2000, 43:995-1000.

14. Hunter DJ, Sharma L, Skaife T: Alignment and osteoarthritis of the knee. J Bone Joint Surg Am 2009, 91(1):85-89.

15. Martin KR, Kuh D, Harris TB, Guralnik JM, Coggon D, Wills AK: Body mass index, occupational activity, and leisure-time physical activity: an exploration of risk factors and modifiers for knee osteoarthritis in the 1946 British birth cohort. BMC Musculoskelet Disord 2013, 14:219. 
16. The global epidemic: IASO/IOTF analysis. http://www.iaso.org/iotf/obesity/ obesitytheglobalepidemic/

17. Bullo M, Garcia-Lorda P, Megias I, Salas-Salvado J: Systemic inflammation, adipose tissue tumor necrosis factor, and leptin expression. Obes Res 2003, 11:525-531.

18. Scharstuhl A, Glansbeek HL, van Beuningen HM, Vitters EL, van der Kraan PM, van den Berg WB: Inhibition of endogenous TGF-beta during experimental osteoarthritis prevents osteophyte formation and impairs cartilage repair. J Immunol 2002, 169:507-514.

19. Mobasheri A: Osteoarthritis year 2012 in review: biomarkers. Osteoarthritis Cartilage 2012, 20:1451-1464.

20. Bitton R: The economic burden of osteoarthritis. Am J Manag Care 2009, 15:S230-235.

21. Zhang Y, Jordan JM: Epidemiology of osteoarthritis. Clin Geriatr Med 2010 26:355-369.

22. Jordan JM, Helmick CG, Renner JB, Luta G, Dragomir AD, Woodard J, Fang F, Schwartz TA, Abbate LM, Callahan LF, et al: Prevalence of knee symptoms and radiographic and symptomatic knee osteoarthritis in African Americans and Caucasians: the Johnston county osteoarthritis project. J Rheumatol 2007, 34:172-180.

23. Farr JN, Going SB, Lohman TG, Rankin L, Kasle S, Cornett M, Cussler E: Physical activity levels in patients with early knee osteoarthritis measured by accelerometry. Arthritis Rheum 2008, 59:1229-1236.

24. Flegal KM, Carroll MD, Ogden CL, Johnson CL: Prevalence and trends in obesity among US adults, 1999-2000. JAMA 2002, 288:1723-1727.

25. Richmond J, Hunter D, Irrgang J, Jones MH, Levy B, Marx R, Snyder-Mackler L, Watters WC 3rd, Haralson RH 3rd, Turkelson CM, et al: Treatment of osteoarthritis of the knee (nonarthroplasty). J Am Acad Orthop Surg 2009, 17:591-600.

26. Zhang W, Moskowitz RW, Nuki G, Abramson S, Altman RD, Arden N, Bierma-Zeinstra S, Brandt KD, Croft P, Doherty M, et al: OARSI recommendations for the management of hip and knee osteoarthritis, part II: OARSI evidence-based, expert consensus guidelines. Osteoarthritis Cartilage 2008, 16:137-162.

27. Hochberg MC, Altman RD, April KT, Benkhalti M, Guyatt G, McGowan J, Towheed T, Welch V, Wells G, Tugwell P: American college of rheumatology 2012 recommendations for the use of nonpharmacologic and pharmacologic therapies in osteoarthritis of the hand, hip, and knee. Arthritis Care Res (Hoboken) 2012, 64:465-474.

28. Jordan KM, Arden NK, Doherty M, Bannwarth B, Bijlsma JW, Dieppe P, Gunther K, Hauselmann H, Herrero-Beaumont G, Kaklamanis P, et al: EULAR recommendations 2003: an evidence based approach to the management of knee osteoarthritis: report of a task force of the standing committee for international clinical studies including therapeutic trials (ESCISIT). Ann Rheum Dis 2003, 62:1145-1155.

29. Zhang W, Nuki G, Moskowitz RW, Abramson S, Altman RD, Arden NK, Bierma-Zeinstra S, Brandt KD, Croft P, Doherty M, et al: OARSI recommendations for the management of hip and knee osteoarthritis: part III: changes in evidence following systematic cumulative update of research published through january 2009. Osteoarthritis Cartilage 2010, 18:476-499.

30. Helmark IC, Mikkelsen UR, Borglum J, Rothe A, Petersen MC, Andersen O, Langberg H, Kjaer M: Exercise increases interleukin-10 levels both intraarticularly and peri-synovially in patients with knee osteoarthritis: a randomized controlled trial. Arthritis Res Ther 2010, 12:R126.

31. Bennell KL, Hinman RS: A review of the clinical evidence for exercise in osteoarthritis of the hip and knee. J Sci Med Sport 2011, 14:4-9.

32. Bosomworth NJ: Exercise and knee osteoarthritis: benefit or hazard? Can Fam Physician 2009, 55:871-878.

33. Roddy E, Zhang W, Doherty M, Arden NK, Barlow J, Birrell F, Carr A, Chakravarty K, Dickson J, Hay E, et al: Evidence-based recommendations for the role of exercise in the management of osteoarthritis of the hip or knee-the MOVE consensus. Rheumatology (Oxford) 2005, 44:67-73.

34. Mundermann A, Dyrby CO, Hurwitz DE, Sharma L, Andriacchi TP: Potential strategies to reduce medial compartment loading in patients with knee osteoarthritis of varying severity: reduced walking speed. Arthritis Rheum 2004, 50:1172-1178.

35. Zhang W, Moskowitz RW, Nuki G, Abramson S, Altman RD, Arden N, Bierma-Zeinstra S, Brandt KD, Croft P, Doherty M, et al: OARSI recommendations for the management of hip and knee osteoarthritis, part l: critical appraisal of existing treatment guidelines and systematic review of current research evidence. Osteoarthritis Cartilage 2007, 15:981-1000.
36. Bartels EM, Lund $H$, Hagen KB, Dagfinrud $H$, Christensen R, DanneskioldSamsoe B: Aquatic exercise for the treatment of knee and hip osteoarthritis. Cochrane Database Syst Rev 2007, 17(4):CD005523.

37. Hinman RS, Heywood SE, Day AR: Aquatic physical therapy for hip and knee osteoarthritis: results of a single-blind randomized controlled trial. Phys Ther 2007, 87:32-43.

38. Lim JY, Tchai E, Jang SN: Effectiveness of aquatic exercise for obese patients with knee osteoarthritis: a randomized controlled trial. PM $R$ 2010, 2:723-731. quiz 793.

39. Wang TJ, Lee SC, Liang SY, Tung HH, Wu SF, Lin YP: Comparing the efficacy of aquatic exercises and land-based exercises for patients with knee osteoarthritis. J Clin Nurs 2011, 20:2609-2622.

40. Wyatt FB, Milam S, Manske RC, Deere R: The effects of aquatic and traditional exercise programs on persons with knee osteoarthritis. J Strength Cond Res 2001, 15:337-340.

41. Tsourlou T, Benik A, Dipla K, Zafeiridis A, Kellis S: The effects of a twenty-four-week aquatic training program on muscular strength performance in healthy elderly women. J Strength Cond Res 2006, 20:811-818.

42. Driver $\mathrm{S}, \mathrm{O}^{\prime}$ Connor J, Lox C, Rees $\mathrm{K}$ : Evaluation of an aquatics programme on fitness parameters of individuals with a brain injury. Brain Inj 2004, 18:847-859

43. Templeton MS, Booth DL, O'Kelly WD: Effects of aquatic therapy on joint flexibility and functional ability in subjects with rheumatic disease. J Orthop Sports Phys Ther 1996, 23:376-381.

44. Wang TJ, Belza B, Elaine Thompson F, Whitney JD, Bennett K: Effects of aquatic exercise on flexibility, strength and aerobic fitness in adults with osteoarthritis of the hip or knee. J Adv Nurs 2007, 57:141-152.

45. Liebs TR, Herzberg W, Ruther W, Haasters J, Russlies M, Hassenpflug J: Multicenter randomized controlled trial comparing early versus late aquatic therapy after total hip or knee arthroplasty. Arch Phys Med Rehabil 2012, 93:192-199.

46. Valtonen A, Poyhonen T, Sipila S, Heinonen A: Maintenance of aquatic training-induced benefits on mobility and lower-extremity muscles among persons with unilateral knee replacement. Arch Phys Med Rehabil 2011, 92:1944-1950.

47. Escalante Y, Saavedra JM, Garcia-Hermoso A, Silva AJ, Barbosa TM: Physical exercise and reduction of pain in adults with lower limb osteoarthritis: a systematic review. J Back Musculoskelet Rehabil 2010, 23:175-186.

48. Rahmann AE, Brauer SG, Nitz JC: A specific inpatient aquatic physiotherapy program improves strength after total hip or knee replacement surgery: a randomized controlled trial. Arch Phys Med Rehabil 2009, 90:745-755.

49. Lee HY: Comparison of effects among Tai-Chi exercise, aquatic exercise, and a self-help program for patients with knee osteoarthritis. Taehan Kanho Hakhoe Chi 2006, 36:571-580.

50. Aquatic physical therapy: running in water decreases stress on the body. J Orthop Sports Phys Ther 2012, 42:445.

51. Verhagen AP, Cardoso JR, Bierma-Zeinstra SM: Aquatic exercise \& balneotherapy in musculoskeletal conditions. Best Pract Res Clin Rheumatol 2012, 26:335-343.

52. Ariyoshi M, Sonoda K, Nagata K, Mashima T, Zenmyo M, Paku C, Takamiya Y, Yoshimatsu $\mathrm{H}$, Hirai $Y$, Yasunaga $\mathrm{H}$, et al: Efficacy of aquatic exercises for patients with low-back pain. Kurume Med J 1999, 46:91-96.

53. Bacon MC, Nicholson C, Binder $\mathrm{H}$, White PH: Juvenile rheumatoid arthritis: aquatic exercise and lower-extremity function. Arthritis Care Res 1991, 4:102-105.

54. Hall J, Grant J, Blake D, Taylor G, Garbutt G: Cardiorespiratory responses to aquatic treadmill walking in patients with rheumatoid arthritis. Physiother Res Int 2004, 9:59-73.

55. Kelly M, Darrah J: Aquatic exercise for children with cerebral palsy. Dev Med Child Neurol 2005, 47:838-842.

56. Kargarfard M, Dehghadani M, Ghias R: The effect of aquatic exercise therapy on muscle strength and Joint's range of motion in hemophilia patients. Int J Prev Med 2013, 4:50-56.

57. Kallberg J: Aquatic therapy brings relief: arthritis sufferers go back to the future to achieve freedom from pain, courtesy of technological advances in an old remedy. Provider 2013, 39:35-37.

58. Cantarero-Villanueva I, Fernandez-Lao C, Cuesta-Vargas Al, Del Moral-Avila R, Fernandez-de-Las-Penas CC, Arroyo-Morales M: The effectiveness of a deep water aquatic exercise program in cancer-related fatigue in breast 
cancer survivors: a randomized clinical trial deep water aquatic exercise in cancer survivors. Arch Phys Med Rehabil 2012, 94(2):221-230.

59. Barakat R, Cordero Y, Coteron J, Luaces M, Montejo R: Exercise during pregnancy improves maternal glucose screen at 24-28 weeks: a randomised controlled trial. Br J Sports Med 2012, 46:656-661.

60. DeMaere JM, Ruby BC: Effects of deep water and treadmill running on oxygen uptake and energy expenditure in seasonally trained cross country runners. J Sports Med Phys Fitness 1997, 37:175-181.

61. Martel GF, Harmer ML, Logan JM, Parker CB: Aquatic plyometric training increases vertical jump in female volleyball players. Med Sci Sports Exerc 2005, 37:1814-1819.

62. Reilly T, Ekblom B: The use of recovery methods post-exercise. J Sports Sci 2005, 23:619-627.

63. Alberton CL, Cadore EL, Pinto SS, Tartaruga MP, da Silva EM, Kruel LF: Cardiorespiratory, neuromuscular and kinematic responses to stationary running performed in water and on dry land. Eur J Appl Physiol 2011, 111:1157-1166.

64. Yazigi F, Pinto S, Colado J, Escalante Y, Armada-Da-Silva P, Brasil R, Alves F: The cadence and water temperature effect on physiological responses during water cycling. European Journal of Sport Science 2013:1-7.

65. Water exercise for arthritis: Low-impact fitness. Mayo Clin Health Lett 2003, 21:4-5.

66. Broman G, Quintana M, Engardt M, Gullstrand L, Jansson E, Kaijser L: Older women's cardiovascular responses to deep-water running. J Aging Phys Act 2006, 14:29-40.

67. Brown SP, Chitwood LF, Beason KR, McLemore DR: Physiological correlates with perceived exertion during deep water running. Percept Mot Skills 1996, 83:155-162.

68. Butts NK, Tucker M, Greening C: Physiologic responses to maximal treadmill and deep water running in men and women. Am J Sports Med 1991, 19:612-614.

69. Chu KS, Rhodes EC: Physiological and cardiovascular changes associated with deep water running in the young. Possible implications for the elderly. Sports Med 2001, 31:33-46.

70. Triplett NT, Colado JC, Benavent J, Alakhdar Y, Madera J, Gonzalez LM, Tella $\checkmark$ : Concentric and impact forces of single-leg jumps in an aquatic environment versus on land. Med Sci Sports Exerc 2009, 41:1790-1796.

71. Phillips VK, Legge $M$, Jones LM: Maximal physiological responses between aquatic and land exercise in overweight women. Med Sci Sports Exerc 2008, 40:959-964.

72. Aquatic Exercise Association: Aquatic fitness professional manual 5 edn Nokomis, FL; 2006

73. Foundation A: Arthritis foundation YMCA aquatic program (AFYAP) and AFYAP PLUS instructor's quides 4th edn. The Arthritis Foundation: Atlanta; 2002

74. Messier SP: Obesity and osteoarthritis: disease genesis and nonpharmacologic weight management. Med Clin North Am 2009, 93:145-159. xi-xii.

75. Altman R, Alarcon G, Appelrouth D, Bloch D, Borenstein D, Brandt K, Brown C, Cooke TD, Daniel W, Feldman D, et al: The American college of rheumatology criteria for the classification and reporting of osteoarthritis of the hip. Arthritis Rheum 1991, 34:505-514.

76. American College of Sports Medicine (ACSM): ACSM's guidelines for exercise testing and prescription. 8th edition. Lippincott: Williams \& Wilkins; 2009.

77. Messier SP, Legault C, Mihalko S, Miller GD, Loeser RF, DeVita P, Lyles M, Eckstein F, Hunter DJ, Williamson JD, Nicklas BJ: The intensive diet and exercise for arthritis (IDEA) trial: design and rationale. BMC Musculoskelet Disord 2009, 10:93.

78. Batterham SI, Heywood S, Keating JL: Systematic review and meta-analysis comparing land and aquatic exercise for people with hip or knee arthritis on function, mobility and other health outcomes. BMC Musculoskelet Disord 2011, 12:123.

79. Silva M, Santos T, Coutinho S, Marcelino M, Vieira P, Tomás R, Carraça E, Minderico C, Sardinha L, Teixeira P: O programa "PESO COMUNITÁRIO. Revista de Informação e Divulgação Científica sobre Doenças do Comportamento Alimentar 2008, 5:1-12.

80. Kellgren JH, Lawrence JS: Radiological assessment of osteo-arthrosis. Ann Rheum Dis 1957, 16:494-502.

81. Turk DC, Dworkin RH, Allen RR, Bellamy N, Brandenburg N, Carr DB, Cleeland C, Dionne R, Farrar JT, Galer BS, et al: Core outcome domains for chronic pain clinical trials: IMMPACT recommendations. Pain 2003, 106:337-345.
82. Mendoza T, Mayne T, Rublee $D$, Cleeland C: Reliability and validity of a modified brief pain inventory short form in patients with osteoarthritis. Eur J Pain 2006, 10:353-361.

83. Ferreira-Valente MA, Pais Ribeiro $J L$, Jensen MP: Further validation of a Portuguese version of the brief pain inventory interference scale. Clínica y Salud 2012, 23:89-96.

84. Azevedo LF, Pereira AC, Dias C, Agualusa L, Lemos L, Romão J, Castro-Lopes JM: Tradução, adaptação cultural e estudo multicêntrico de validação de instrumentos para rastreio e avaliação do impacto da dor crónica. Dor 2007, 15:6-37.

85. Roos EM, Lohmander LS: The knee injury and osteoarthritis outcome score (KOOS): from joint injury to osteoarthritis. Health Qual Life Outcomes 2003, 1:64.

86. Goncalves RS, Cabri J, Pinheiro JP, Ferreira PL: Cross-cultural adaptation and validation of the Portuguese version of the knee injury and osteoarthritis outcome score (KOOS). Osteoarthritis Cartilage 2009, 17:1156-1162.

87. Gandek B, Ware JE, Aaronson NK, Apolone G, Bjorner JB, Brazier JE, Bullinger M, Kaasa S, Leplege A, Prieto L, Sullivan M: Cross-validation of item selection and scoring for the SF-12 health survey in nine countries: results from the IQOLA project. International Quality of Life Assessment. J Clin Epidemiol 1998, 51:1171-1178.

88. Wee CC, Davis RB, Hamel MB: Comparing the SF-12 and SF-36 health status questionnaires in patients with and without obesity. Health Qual Life Outcomes 2008, 6:11.

89. Ferreira P: Avaliação psicométrica e adaptação cultural e linguística de instrumentos de medição em saúde: princípios metodológicos gerais. Centro de Estudos e Investigação em Saúde da Universidade de Coimbra; 1998.

90. Ferreira P: Criação da versão Portuguesa do SF-36 - parte II - testes de validação. Acta Med Port 2000, 13:119-127.

91. Beck AT, Steer RA, Ball R, Ranieri W: Comparison of beck depression inventories -IA and -II in psychiatric outpatients. J Pers Assess 1996, 67:588-597.

92. Campos RC, Goncalves B: The Portuguese version of the beck depression inventory-II (BDI-II) preliminary psychometric data with two nonclinical samples. Eur J Psychol Assess 2011, 27:258-264.

93. Beck AT, Steer RA: Internal consistencies of the original and revised beck depression inventory. J Clin Psychol 1984, 40:1365-1367.

94. Brooks D, Solway S, Gibbons WJ: ATS statement on six-minute walk test. Am J Respir Crit Care Med 2003, 167:1287.

95. Beriault K, Carpentier AC, Gagnon C, Menard J, Baillargeon JP, Ardilouze JL, Langlois MF: Reproducibility of the 6-minute walk test in obese adults. Int J Sports Med 2009, 30:725-727.

96. Goncalves RS, Pinheiro JP, Cabri J: Evaluation of potentially modifiable physical factors as predictors of health status in knee osteoarthritis patients referred for physical therapy. Knee 2012, 19:373-379.

97. Bennell K, Dobson F, Hinman R: Measures of physical performance assessments: self-paced walk test (SPWT), stair climb test (SCT), Six-minute walk test (6MWT), chair stand test (CST), timed Up \& Go (TUG), sock test, lift and carry test (LCT), and car task. Arthritis Care Res (Hoboken) 2011, 63(11):S350-370.

98. Enright PL, McBurnie MA, Bittner V, Tracy RP, McNamara R, Arnold A, Newman AB: The 6-min walk test: a quick measure of functional status in elderly adults. Chest 2003, 123:387-398.

99. Escalante Y, Garcia-Hermoso A, Saavedra JM: Effects of exercise on functional aerobic capacity in lower limb osteoarthritis: a systematic review. J Sci Med Sport 2011, 14:190-198.

100. Schlenk EA, Lias JL, Sereika SM, Dunbar-Jacob J, Kwoh CK: Improving physical activity and function in overweight and obese older adults with osteoarthritis of the knee: a feasibility study. Rehabil Nurs 2011, 36:32-42.

101. Jones CJ, Rikli RE, Max J, Noffal G: The reliability and validity of a chair sit-and-reach test as a measure of hamstring flexibility in older adults. Res Q Exerc Sport 1998, 69:338-343.

102. Rikli RE, Jones $\mathrm{CJ}$ : The development and validation of a functional fitness test for community-residimg older adults. J Aging Phys Act 1999, 7:129-161.

103. Bohannon RW: Sit-to-stand test for measuring performance of lower extremity muscles. Percept Mot Skills 1995, 80:163-166.

104. Bohannon RW: Test-retest reliability of the five-repetition sit-to-stand test: a systematic review of the literature involving adults. J Strength Cond Res 2011, 25:3205-3207.

105. Rejeski W, Miller M, Foy C, Messier S, Rapp S: Self-efficacy and the progression of functional limitations and self-reported disability in older 
adults with knee pain. Journal of Gerontology: Social Sciences 2001, 56B:S261-S265.

106. Rejeski W, Ettinger W, Schumaker S, James P, Burns R, Elam J: Assessing performance-related disability in patients with knee osteoarthritis. Osteoarthritis Cartilage 1995, 3:157-167.

107. Rejeski W, Craven T, Ettinger W, McFarlane M, Shumaker S: Self-efficacy and pain in disability with osteoarthritis of the knee. J Gerontol Psychol Sci 1996, 51B:P24-P29.

108. Miller M, Rejeski W, Messier S, Loeser R: Modifiers of change in physical functioning in older adults with knee pain: the observational arthritis study in seniors (OASIS). Arthritis Care Res 2001, 45:331-339.

109. Messier S, Glasser J, Ettinger W, Craven T, Miller M: Declines in strength and balance in older adults with chronic knee pain: A 30 month longitudinal, observational study. Arthritis \& Rheumatism 2002, 47:141-148.

110. Brandt K, Heilman D, Slemenda C, Katz B, Mazzuca S, Braunstein E, Byrd D: A comparison of lower extremity muscle strength, obesity, and depression scores in elderly subjects with knee pain with and without radiographic evidence of knee osteoarthritis. J Rheumatol 2000, 27:1937-1946.

111. Sharma L, Song J, Dunlop D, Felson D, Lewis CE, Segal N, Torner J, Cooke TD, Hietpas J, Lynch J, Nevitt M: Varus and valgus alignment and incident and progressive knee osteoarthritis. Ann Rheum Dis 2010, 69:1940-1945.

112. Barbat-Artigas S, Rolland Y, Zamboni M, Aubertin-Leheudre M: How to assess functional status: a new muscle quality index. J Nutr Health Aging 2012, 16:67-77.

113. Deforche B, Lefevre J, De Bourdeaudhuij I, Hills AP, Duquet W, Bouckaert J: Physical fitness and physical activity in obese and nonobese Flemish youth. Obes Res 2003, 11:434-441.

114. Baptista F, Silva A, Marques E, Mota J, Santos R, Vale S, Ferreira J, Raimundo A, Moreira H: Observatorio nacional da actividade física e do desporto: livro verde da aptidão física. Lisbon, Portugal: Instituto do Desporto de Portugal (IDP); 2011. IDP.

115. Marfell-Jones M, Olds T, Stewart A, Lindsay Carter JE: International standards for anthropometric assessment. ISAK.: Potchefstroom; 2006.

116. Lohman TG, Roche AF, Martorell R: Anthropometric standardization reference manual champaing. Human Kinetics Brooks: Illions; 1988.

117. Pheasant S, Haslegrave CM: Bodyspace anthropometry, ergonomics, and the design of work. Boca Raton, FL: Taylor and Francis; 2006.

118. Riserus U, Arnlov J, Brismar K, Zethelius B, Berglund L, Vessby B: Sagittal abdominal diameter is a strong anthropometric marker of insulin resistance and hyperproinsulinemia in obese men. Diabetes Care 2004, 27:2041-2046.

119. Winter D: The biomechanics and motor control of human gait: normal, elderly and pathological. Ontario: University of Waterloo Press; 1991.

120. Block JA, Shakoor N: The biomechanics of osteoarthritis: implications for therapy. Curr Rheumatol Rep 2009, 11:15-22.

121. Messier SP: Osteoarthritis of the knee and associated factors of age and obesity: effects on gait. Med Sci Sports Exerc 1994, 26:1446-1452.

122. Sharma L, Hurwitz DE, Thonar EJ, Sum JA, Lenz ME, Dunlop DD, Schnitzer TJ, Kirwan-Mellis G, Andriacchi TP: Knee adduction moment, serum hyaluronan level, and disease severity in medial tibiofemoral osteoarthritis. Arthritis Rheum 1998, 41:1233-1240.

123. Kumar D, Manal KT, Rudolph KS: Knee joint loading during gait in healthy controls and individuals with knee osteoarthritis. Osteoarthritis Cartilage 2013, 21:298-305.

124. Teichtahl AJ, Wluka AE, Morris ME, Davis SR, Cicuttini FM: The relationship between the knee adduction moment and knee pain in middle-aged women without radiographic osteoarthritis. J Rheumatol 2006, 33:1845-1848.

125. Thorp LE, Sumner DR, Block JA, Moisio KC, Shott S, Wimmer MA: Knee joint loading differs in individuals with mild compared with moderate medial knee osteoarthritis. Arthritis Rheum 2006, 54:3842-3849.

126. Thorp LE, Sumner DR, Wimmer MA, Block JA: Relationship between pain and medial knee joint loading in mild radiographic knee osteoarthritis. Arthritis \& Rheumatism-Arthritis Care \& Research 2007, 57:1254-1260.

127. Yamada H, Koshino T, Sakai N, Saito T: Hip adductor muscle strength in patients with varus deformed knee. Clin Orthop Relat Res 2001:179-185.

128. Craig CL, Marshall AL, Sjostrom M, Bauman AE, Booth ML, Ainsworth BE, Pratt M, Ekelund U, Yngve A, Sallis JF, Oja P: International physical activity questionnaire: 12-country reliability and validity. Med Sci Sports Exerc 2003, 35:1381-1395.
129. Rutten A, Abu-Omar K: Prevalence of physical activity in the European Union. Soz Praventivmed 2004, 49:281-289.

130. Rutten A, Abu-Omar K: Perceptions of environmental opportunities for physical activity in the European Union. Soz Praventivmed 2004, 49:310-317.

131. Lee PH, Macfarlane DJ, Lam TH, Stewart SM: Validity of the international physical activity questionnaire short form (IPAQ-SF): a systematic review. Int J Behav Nutr Phys Act 2011, 8:115.

132. Guidelines for data processing and analysis of the international physical activity questionnaire (IPAQ)- short and long forms. vol. 2006. https://sites. google.com/site/theipaq/, 2005.

133. Wadden TA, Foster GD: Weight and lifestyle inventory (WALI). Obesity (Silver Spring) 2006, 14(2):99S-118S.

134. Teixeira P, Silva M: Repensar o PESO: princípios e métodos testados para controlar o peso.; 2009

\section{doi:10.1186/1471-2474-14-320}

Cite this article as: Yázigi et al:: The PICO project: aquatic exercise for knee osteoarthritis in overweight and obese individuals. $B M C$

Musculoskeletal Disorders 2013 14:320.

\section{Submit your next manuscript to BioMed Central and take full advantage of:}

- Convenient online submission

- Thorough peer review

- No space constraints or color figure charges

- Immediate publication on acceptance

- Inclusion in PubMed, CAS, Scopus and Google Scholar

- Research which is freely available for redistribution 